\title{
Erratum: Evaluation of niobium as candidate electrode material for dc high voltage photoelectron guns [Phys. Rev. ST Accel. Beams 15, 083502 (2012)]
}

M. BastaniNejad, Md. Abdullah Mohamed, A. A. Elmustafa, P. Adderley, J. Clark, S. Covert, J. Hansknecht, C. Hernandez-Garcia, M. Poelker, R. Mammei, K. Surles-Law, and P. Williams (Received 13 January 2014; published 18 February 2014)

DOI: 10.1103/PhysRevSTAB.17.029901

PACS numbers: 29.25.Bx, 79.70.+q, 29.25.Pj, 99.10.Cd

The calculated values for the emission area of field emitters, $A_{e}$, in Table III are incorrect. Corrected values are shown below:

TABLE III

\begin{tabular}{|c|c|c|c|c|c|c|c|c|}
\hline & FGNb1 & FGNb2 & $\mathrm{SCNb} 1 *$ & $\mathrm{SCNb} 2$ & LGNb1* & LGNb2 & DPP-SS1 & DPP-SS2 \\
\hline Intercept Pre-Kr & -17.8 & -15.8 & $\ldots$ & -18.5 & $\ldots$ & -15.5 & -17.6 & -18.3 \\
\hline Intercept Post-Kr & -15.5 & -20.3 & $\ldots$ & -17.4 & $\ldots$ & -13.7 & -22.6 & -15.4 \\
\hline$A_{e}$ Pre-Kr $\left(\mathrm{m}^{2}\right)$ & $6.8 \mathrm{E}-20$ & $2.1 \mathrm{E}-16$ & $\ldots$ & 8.1E-20 & $\ldots$ & $4.5 \mathrm{E}-17$ & $1.1 \mathrm{E}-19$ & 7.7E-20 \\
\hline$A_{e}$ Post-Kr $\left(\mathrm{m}^{2}\right)$ & $5.1 \mathrm{E}-16$ & $2.6 \mathrm{E}-22$ & $\ldots$ & $2.1 \mathrm{E}-16$ & $\ldots$ & 5.3E-14 & 4.6E-19 & $8.6 \mathrm{E}-16$ \\
\hline
\end{tabular}

The corrected values for $A_{e}$ are larger than originally reported, and closer to typical values frequently reported in literature. However, it is still unclear if field emission originates from single or multiple emitters. The new values do not alter the conclusions of the paper.

Published by the American Physical Society under the terms of the Creative Commons Attribution 3.0 License. Further distribution of this work must maintain attribution to the author(s) and the published articles title, journal citation, and DOI. 